\title{
PURIFICAÇÃO DE LEVEDURAS EXTRAÍDAS DA POLPA DE MAÇÃ VERDE (MALUS DOMESTICA) E PROSPECÇÃO DA SUA UTILIZAÇÃO NA PRODUÇÃO DE BEBIDAS FERMENTADAS.
}

\author{
$\underline{\text { Paula Grazyella Coelho Silva }}{ }^{1}$; José Ailton Conceição Bispo ${ }^{2}$; Aurora Britto de \\ Andrade $^{3}$ e Fernanda Antônia de Souza Oliveira ${ }^{4}$ \\ 1. Bolsista PROBIC, Graduanda em Engenharia de Alimentos, Universidade Estadual de Feira de Santana, e-mail: \\ paulagcoelhos@gmail.com \\ 2. Orientador, Departamento de Tecnologia, Universidade Estadual de Feira de Santana, e-mail: \\ ailton_bispo@hotmail.com \\ 3. Graduanda em Engenharia de Alimentos, Departamento de Tecnologia, Universidade Estadual de Feira de \\ Santana, e-mail: aurora-andrade@ hotmail.com \\ 4. Graduanda em Engenharia de Alimentos, Departamento de Tecnologia, Universidade Estadual de Feira de \\ Santana, e-mail: fernanda.aso@ hotmail.com
}

PALAVRAS-CHAVE: fermentação; álcool; levedura.

\section{INTRODUÇÃO}

A fermentação alcoólica é um processo anaeróbico que se inicia devido à ação das leveduras que usam os açúcares do mosto para seu crescimento e multiplicação, dando como resultado a formação de álcool e anidro carbônico. Enquanto existe oxigênio no mosto, a levedura cresce e se multiplica. Quando este acaba começa a produção de álcool e $\mathrm{CO}_{2}$ (Santos et al., 2008). Durante a fermentação alcoólica também são produzidos outros metabólitos fermentativos e biomassa. Sua produção sempre é pequena quando comparada com a quantidade de açúcares convertidos em etanol e gás carbônico (Barre et al., 2000).

$\mathrm{Na}$ fermentação alcoólica, o crescimento celular está diretamente relacionado com a formação do produto, que é o álcool. Desta forma, tanto o crescimento da levedura como a formação do álcool são influenciados pelas condições que o meio oferece (Santos et al., 2008). A fermentação alcoólica constitui uma das etapas mais importantes para elaboração de vinhos e bebidas fermentadas, podendo ser conduzida com várias leveduras. Mesmo que, em maior ou em menor quantidade, possa intervir certo número de espécies e inclusive de gêneros de leveduras, o papel principal é desempenhado pela Saccharomyces cerevisiae (Barre et al., 2000).

Objetivando a melhoria no processamento de cervejas e vinhos pelo processo intermitente, mais conhecido como batelada, utilizando-se como adjunto fermentativo a suplementação nutricional a partir de frutas, o presente trabalho visa obter condições para compor um setor de modelagem matemático-estatístico capaz de aperfeiçoar as condições de produção e ao mesmo tempo diversificar produtos fermentados provenientes de frutos climatéricos, utilizando-se o programa de software Cadmo desenvolvido pelo Professor Ailton Bispo. Portanto, o presente trabalho propõe avaliar as diferentes condições de suplementação nutricional do mosto cervejeiro frutado de Maçã Verde (Malus domestica), de acordo com as condições de fermentação padrão

\section{METODOLOGIA}


No primeiro momento foi realizada a separação e purificação de leveduras, seguida pela análise fermentativa com o mosto da maçã verde nas concentrações 0,10 , 20 e 30\% com o acréscimo da levedura Red Star Montrachet e determinação da concentração celular do mosto, quantidade de etanol produzido durante a fermentação até a estabilização do ${ }^{\circ}$ Brix. A modelagem termodinâmica e análises dos dados colhidos experimentalmente foram feitas utilizando o software Cadmo (Versão inicial para testes).

\section{RESULTADOS E/OU DISCUSSÃO}

A superfície gerada no programa (Figura 1) descreve o crescimento celular variando com a concentração de polpa utilizada e com o tempo decorrido de fermentação. Nele é possível ter um panorama de como a fermentação se comportou com as diferentes porcentagens de polpa utilizadas como adjunto.

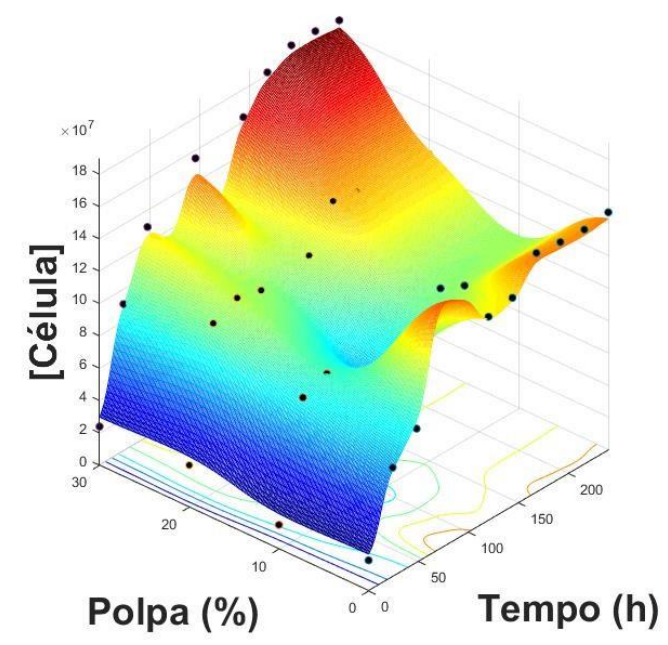

Figura 1: Superfície de crescimento celular variando com o tempo e concentração de polpa de maçã verde.

É possível ainda observar o comportamento da velocidade de crescimento celular variando com as concentrações de polpa (Figura 2). O crescimento ocorreu de forma mais acelerada nas primeiras horas de fermentação, sem grande diferença entre os mostos, com exceção da polpa de $10 \%$ que apresentou a maior velocidade de crescimento celular, porém seguida da maior queda na velocidade de crescimento. 

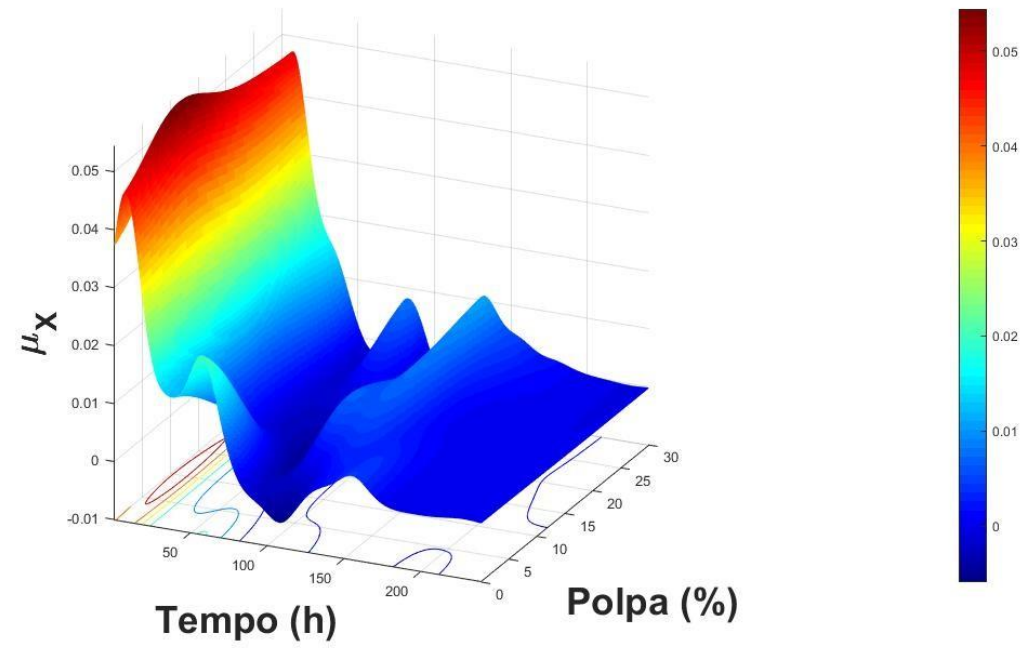

Figura 2: Variação da velocidade de crescimento celular com o tempo e concentração de polpa.

Analisando agora a variação de substrato ao longo do processo fermentativo (Figura 3), observa-se que a adição de polpa ao mosto reduz o ${ }^{\circ}$ Brix inicial do mesmo proporcionalmente ao aumento da sua concentração.

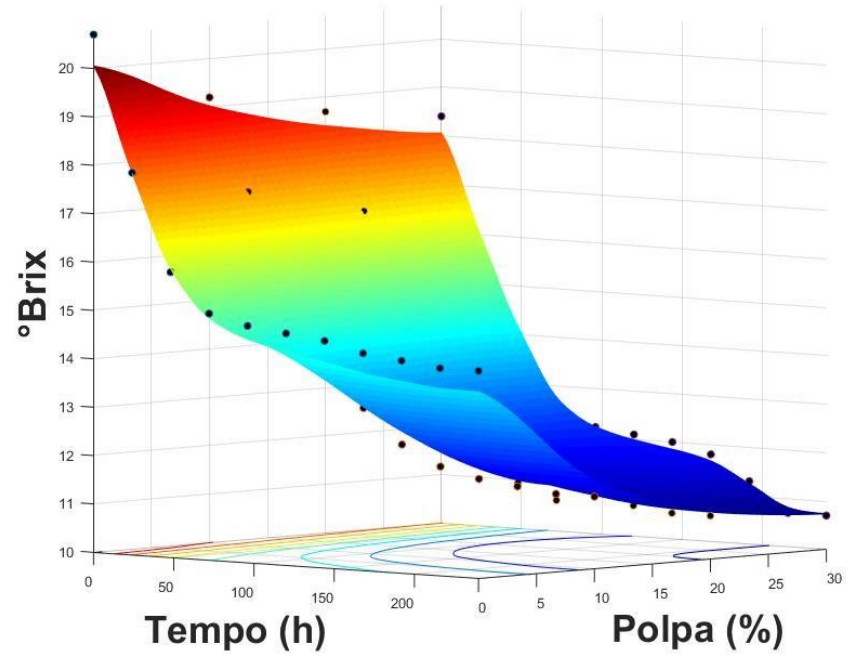

Figura 3: Variação de ${ }^{\circ}$ Brix com tempo e concentração de polpa.

Por fim, foi analisado a produção de etanol (Figura 4), produto de interesse da fermentação. $\mathrm{O}$ aumento no teor de etanol aconteceu de forma similar em todos os mostos, observando-se apenas uma maior produção no mosto contendo 30\% de polpa quando comparado aos demais, o que era esperado devido a maior redução de ${ }^{\circ}$ Brix neste mosto. 


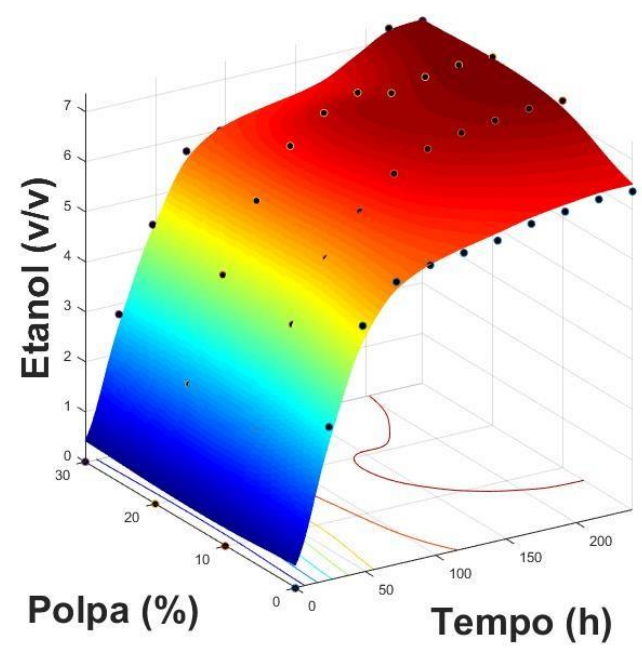

Figura 4: Produção de etanol variando com o tempo e concentração de polpa.

\section{CONSIDERAÇÕES FINAIS}

No trabalho, concluiu-se que a polpa de maçã verde obteve sim bons resultados como adjunto de fermentação. O mosto contendo $30 \%$ de polpa apresentou melhor ação fermentativa, com maior consumo do substrato oferecido e, consequentemente, maior produção de etanol quando comparada aos demais. Entretanto, esta ação só foi observada em maiores proporções para concentrações de polpa acima de $10 \%$, visto que esta concentração, quando comparada ao mosto de controle $(0 \%$ de polpa) possuiu menor crescimento celular, e pequena diferença no consumo de substrato e produção de etanol.

\section{REFERENCIAS}

SANTOS, A. M. 2008. et al. Estudo da influência da complementação de nutrientes no mosto sobre o processo de fermentação alcoólica em batelada.

BARRE, P.; BLONDIN, B.; DEQUIN, S.; FEUILLAT, M.; SABLAYROLLES, J.M.; SALMON, J.M. 2000. La levadura de fermnetación alcohólica. In: FLANZY, C. Enología: fundamentos científicos e tecnológicos. Madrid: Mundi-Prensa e AMV, p. 274-315. 